\title{
TNF- $\alpha$ and IL-10 levels in tracheobronchial lavage of ventilated preterm infants and subsequent lung function
}

\section{A.L. Corso, P.M.C. Pitrez, D.C. Machado, \\ R.T. Stein and M.H. Jones}

\author{
Departamento de Pediatria, Faculdade de Medicina, \\ Pontifícia Universidade Católica do Rio Grande do Sul, Porto Alegre, RS, Brasil
}

\section{Correspondence}

M.H. Jones

Hospital São Lucas

Instituto de Pesquisas Biomédicas

PUC-RS

Av. Ipiranga, 6690

90610-000 Porto Alegre, RS

Brasil

Fax: +55-51-3384-5104

E-mail: mhjones@pucrs.br

Received March 9, 2006

Accepted January 29, 2007

\begin{abstract}
The role of airway inflammation in ventilated preterm newborns and the risk factors associated with the development of chronic lung disease are not well understood. Our objective was to analyze the association of the airway inflammatory response in ventilated preterm infants by serial measurements of TNF- $\alpha$ and IL-10 in tracheobronchial lavage (TBL) with perinatal factors and lung function measured early in life. A series of TBL samples were collected from ventilated preterm infants (less than 32 weeks of gestational age) and concentrations of TNF- $\alpha$ and IL-10 were measured by ELISA. Pulmonary function tests were performed after discharge by the raised volume rapid compression technique. Twenty-five subjects were recruited and 70 TBL samples were obtained. There was a significant positive association between TNF- $\alpha$ and IL-10 levels and length of time between the rupture of the amniotic membranes and delivery $(r=0.65$, $\mathrm{P}=0.002$, and $\mathrm{r}=0.57, \mathrm{P}<0.001$, respectively). Lung function was measured between 1 and 22 weeks of corrected age in 10 patients. Multivariable analysis with adjustment for differences in lung volume showed a significant negative association between TNF- $\alpha$ levels and forced expiratory flow $\left(\mathrm{FEF}_{50} ; \mathrm{r}=-0.6 ; \mathrm{P}=0.04\right), \mathrm{FEF}_{75}(\mathrm{r}=-0.76 ; \mathrm{P}$ $=0.02), \mathrm{FEF}_{85}(\mathrm{r}=-0.75 ; \mathrm{P}=0.03), \mathrm{FEF}_{25-75}(-0.71 ; \mathrm{P}=0.02)$, and $\mathrm{FEV}_{0.5}(\mathrm{r}=-0.39 ; \mathrm{P}=0.03)$. These data suggest that TNF- $\alpha$ levels in the airways during the first days of life were associated with subsequent lung function abnormalities measured weeks or months later.
\end{abstract}

\section{Introduction}

During the last two decades, therapeutic advances have been associated with a significant increase in survival rates of preterm infants. The use of prenatal corticosteroids, postnatal surfactant treatment and improved ventilation strategies has been responsible
Key words

- Inflammation

- Newborn

- Chronic lung disease

- Interleukin-10

- Tumor necrosis factor- $\alpha$

- Prematurity for the increase of survival rates $(1,2)$. However, despite the advances in perinatal care and the decrease in mortality rates, the prevalence of chronic lung disease (CLD) of prematurity did not decrease $(3,4)$.

Children born prematurely are more vulnerable to respiratory diseases during infancy, presenting a greater prevalence of 
lower airway viral infections, with recurrent hospital admissions in early life $(5,6)$. Premature rupture of membranes, inflammatory response to infections, mechanical ventilation, and supplemental oxygen have been implicated as causative perinatal events associated with persistent respiratory morbidity in this group of patients (7-13).

The contribution of airway inflammation to the development of CLD of prematurity has been extensively studied (10,14-17). There is a dynamic and complex balance between pro- and anti-inflammatory cytokines in the human immune system. Previous studies on premature infants have shown that an increase of TNF- $\alpha$ in tracheal secretions, among other pro-inflammatory cytokines, was associated with the length of mechanical ventilation (18) and the development of CLD (19-21).

The role of the anti-inflammatory cytokines is less clear. Recent studies have demonstrated that preterm infants with respiratory distress do produce significant amounts of IL-10 in the lower airways and the presence of this anti-inflammatory cytokine was not able to prevent the development of chronic lung disease of prematurity (4). Jones et al. (22) were unable to detect IL-10 in most of the airway samples from preterm infants. This observation agrees with a study showing that the control of airway inflammation by this cytokine is limited in infants (23).

Although the association between early pulmonary inflammatory response and CLD has been shown, this clinical outcome has limited sensitivity. Measurements of maximal flows can be performed in infants and offer an objective assessment of lung development and the degree of airway obstruction resulting from perinatal insults. This method offers a clear advantage over a clinical qualitative classification of CLD. Therefore, the objective assessment of lung function may indicate the association between inflammation and subsequent lung growth even in infants with few or no respiratory symptoms. Furthermore, measurements of maximal flows may identify associations between perinatal factors such as gestational age, birth weight and mechanical ventilation and subtle lung function abnormalities, resulting in new strategies for the prevention and treatment of CLD (24).

The objective of the present study was to determine if there is an association of the concentration of the cytokines TNF- $\alpha$ and IL-10 in the tracheobronchial lavage (TBL) of ventilated preterm infants with possible perinatal risk factors and lung function measured early in life.

\section{Subjects and Methods}

\section{Subjects}

Preterm infants with less than 32 weeks of gestation, born at the Neonatal Intensive Care Unit of Hospital São Lucas, Porto Alegre, RS, Brazil, from November 2001 to November 2002, who required mechanical ventilation in the first $24 \mathrm{~h}$ of life due to respiratory distress, were included. Preterm infants with congenital malformations and those who required mechanical ventilation for less than $24 \mathrm{~h}$ were excluded.

Gestational data were collected from the medical charts and by interviews with the mother. Medical charts were reviewed daily by the principal investigator (ALC) during hospitalization.

Gestational age was obtained by the date of the last menstrual period or early obstetric ultrasound, and confirmed by assessment of maturity of the preterm infant by the New Ballard method. Maternal infection was defined by the presence of fever, abnormal white blood cell counts, positive blood culture, clinical signs of chorioamnionitis, or urinary tract infection. Hyaline membrane disease (HMD) and sepsis were diagnosed by the Neonatal Intensive Care Unit (NICU) staff on the basis of clinical and radiologic 
criteria. CLD was defined as oxygen requirement up to 36 weeks of postmenstrual age and characteristic chest X-ray abnormalities.

\section{Sample collection}

TBL was collected within the first $48 \mathrm{~h}$ of endotracheal intubation. The samples were collected during routine endotracheal suction, which was indicated for clinical reasons. After instillation of $0.5 \mathrm{~mL}$ normal saline through the endotracheal tube, the ventilator was reconnected. After 3-4 breath cycles, a polyethylene catheter (6 French gauge) was introduced through the endotracheal tube and gentle suction was applied into a mucus trap. After aspiration, the catheter was flushed with $1 \mathrm{~mL}$ normal saline. Samples from preterm infants who had received surfactant therapy were collected at least $8 \mathrm{~h}$ after surfactant administration.

\section{Cytokine determination}

Samples were centrifuged at $2000 \mathrm{rpm}$ for $2 \mathrm{~min}$ and the supernatant was removed and stored at $-80^{\circ} \mathrm{C}$ for further cytokine analysis. Supernatant concentrations of TNF- $\alpha$ and IL-10 were measured by ELISA, according to manufacturer instructions (Pharmingen, San Diego, CA, USA). The detection limit of TNF- $\alpha$ and IL-10 was $7.8 \mathrm{pg} /$ $\mathrm{mL}$. When cytokine levels were not detected, half the limit of detection $(3.9 \mathrm{pg} / \mathrm{mL})$ was considered for statistical analysis. TNF- $\alpha$ and IL-10 levels are reported as $\mathrm{pg} / \mathrm{mL}$ of TBL sample (25).

\section{Lung function}

Infant pulmonary function tests were assessed by the rapid thoracic compression technique with raised lung volumes (26). Briefly, after recording weight and length, infants were sedated with choral hydrate $(50-80 \mathrm{mg} / \mathrm{kg})$ and placed in the supine posi- tion, with an inflatable jacket wrapped around their abdomen and chest. Lung inflation pressure was set at $30 \mathrm{cmH}_{2} \mathrm{O}$ and thoracic compression was initiated and maintained until a residual volume was reached. Forced expiratory maneuvers were repeated with increases of 5 to $10 \mathrm{cmH}_{2} \mathrm{O}$ in jacket pressure until maximum expiratory flows were obtained. The best curve was that with the highest product of forced vital capacity and forced expiratory flow rate $\left(\mathrm{FEF}_{25-75}\right)$.

\section{Statistical analysis}

Quantitative variables are reported as mean \pm SD or median and interquartile according to variable distribution. Qualitative data are reported as percent. For comparison with normal values, lung function variables were converted to $\mathrm{Z}$-score using regression and variance equations (27). Multiple linear regression was used to test the association of cytokine levels with perinatal factors and lung function.

The study was approved by the Ethics Committee of Hospital São Lucas and all parents gave written informed consent for their children to participate in the study.

\section{Results}

Thirty-three preterm infants were recruited from November 2001 to November 2002. There was no exclusion due to congenital malformations. Eight patients were not included in the study because they needed less than $24 \mathrm{~h}$ of mechanical ventilation. Twenty-five preterm infants were enrolled. The characteristics of the subjects are presented in Table 1. Thirteen patients died before discharge from the NICU and one patient during follow-up. Deaths in the NICU were associated with sepsis (all patients), 3 with pulmonary hemorrhage and pneumothorax, 1 with intraventricular hemorrhage, 6 with patent ductus arteriosus, 4 with renal failure, and 1 with pneumonia. Of the 12 
patients discharged, two (18\%) developed CLD. None of the patients was discharged requiring oxygen therapy.

Table 1. Characteristics of the subjects studied.

\begin{tabular}{lc}
\hline Characteristics & \\
\hline Birth weight (g) & $920(515$ to 1350$)$ \\
Gestational age (weeks) & $28(23$ to 30$)$ \\
Gender (male) & $9(36 \%)$ \\
Small for gestational age & $4(16 \%)$ \\
Membrane rupture $>18 \mathrm{~h}$ & $5(20 \%)$ \\
Hyaline membrane disease & $19(76 \%)$ \\
Patent ductus arteriosus & $14(56 \%)$ \\
Infection (maternal) & $10(40 \%)$ \\
CPAP (days) & $2.0(0$ to 30$)$ \\
Mechanical ventilation (days) & $5.0(1$ to 39$)$ \\
Supplementary oxygen (days) & $9(2$ to 83$)$ \\
&
\end{tabular}

Data are reported as median with range in parentheses or as number with percent in parentheses for 25 subjects during the observation period from November 2001 to November 2002. CPAP = continuous positive air pressure.

\section{Cytokine analysis}

Seventy TBL samples were obtained from the 25 patients included in the study. Fortyseven $(67 \%)$ of the samples collected had detectable TNF- $\alpha$ levels and 18 (26\%) had detectable IL-10 levels. The cytokine levels in TBL during the period of sample collection did not show any specific pattern or distribution.

In the TBL samples collected on day 2 from 22 patients there was a significant positive correlation between both TNF- $\alpha$ and IL-10 concentrations and the length of time between the rupture of the amniotic membranes and delivery $(\mathrm{r}=0.65, \mathrm{P}=0.002$ and $\mathrm{r}=0.57, \mathrm{P}<0.001$, respectively). There was no significant association of TNF- $\alpha$ and IL10 levels with gestational age, birth weight, HMD, mechanical ventilation time, duration of oxygen supply, or death.

Table 2. Characteristics of the patients submitted to lung function tests.

\begin{tabular}{|c|c|c|c|c|c|c|c|c|c|c|}
\hline & \multicolumn{10}{|c|}{ Subjects } \\
\hline & 1 & 2 & 3 & 4 & 5 & 6 & 7 & 8 & 9 & 10 \\
\hline \multicolumn{11}{|l|}{ Neonatal characteristics } \\
\hline Sex & $\mathrm{F}$ & $\mathrm{F}$ & M & $\mathrm{F}$ & M & $\mathrm{F}$ & $\mathrm{F}$ & $\mathrm{F}$ & $\mathrm{F}$ & $\mathrm{F}$ \\
\hline Gestational age (weeks) & 25 & 28 & 29 & 26 & 28 & 27 & 28 & 29 & 29 & 24 \\
\hline Birth weight $(\mathrm{g})$ & 1060 & 975 & 1325 & 810 & 990 & 945 & 750 & 1180 & 1350 & 655 \\
\hline Oxygen supplementation (days) & 72 & 6 & 5 & 7 & 27 & 50 & 41 & 34 & 9 & 83 \\
\hline Mechanical ventilation (days) & 11 & 1 & 2 & 3 & 7 & 18 & 1 & 1 & 2 & 39 \\
\hline IL-10 (pg/mL) & 38 & 19 & 31 & 16 & 24 & 33 & 60 & 1179 & 1073 & 39 \\
\hline TNF- $\alpha(p g / m L)$ & 381 & 259 & 418 & 230 & 1366 & 1074 & 1022 & 32 & 21 & 643 \\
\hline \multicolumn{11}{|l|}{ Lung function tests } \\
\hline Age at test (weeks) & 7.0 & 11.3 & 1.1 & 12.3 & 8.1 & 10.6 & 21.7 & 15.6 & 14.1 & 5.0 \\
\hline Length at test $(\mathrm{cm})$ & 52 & 53 & 51.5 & 51 & 53 & 55.5 & 61.5 & 61 & 62 & 53 \\
\hline $\mathrm{FVC}(\mathrm{mL})$ & 150 & 145 & 97 & 125 & 189 & 192 & 192 & 167 & 189 & 103 \\
\hline $\mathrm{FEF}_{50}(\mathrm{~mL} / \mathrm{s})$ & 231 & 258 & 209 & 131 & 152 & 302 & 280 & 270 & 450 & 133 \\
\hline $\mathrm{FEF}_{75}(\mathrm{~mL} / \mathrm{s})$ & 95 & 142 & 109 & 53 & 15 & 123 & 96 & 129 & 352 & 43 \\
\hline $\mathrm{FEF}_{85}(\mathrm{~mL} / \mathrm{s})$ & 35 & 92 & 73 & 25 & 4 & 51 & 50 & 72 & 244 & 20 \\
\hline $\mathrm{FEF}_{25-75}(\mathrm{~mL} / \mathrm{s})$ & 202 & 231 & 184 & 114 & 70 & 258 & 233 & 238 & 439 & 104 \\
\hline $\mathrm{FEV}_{0.5}(\mathrm{~mL})$ & 114 & 120 & 86 & 83 & 116 & 146 & 144 & 131 & 179 & 75 \\
\hline
\end{tabular}

$\mathrm{IL}-10=$ concentration of interleukin 10 in tracheobronchial lavage (TBL) on day two; TNF- $\alpha=$ concentration of tumor necrosis factor- $\alpha$ in TBL on day two; FVC = forced vital capacity; FEF = forced expiratory flow rate; FEV $=$ forced expiratory volume. 


\section{Infant pulmonary function tests}

Lung function was successfully measured in 10 of the 11 surviving patients with a median birth weight of $920 \mathrm{~g}$ (range: 515 to $1350 \mathrm{~g}$ ) and a median gestational age of 28 weeks (24 to 29 weeks). Nine had HMD and required a surfactant. The patients were tested at a median corrected age of 10.9 weeks (range: 1.1 to 21.7 weeks), with $53 \mathrm{~cm}$ of length (range: 51 to $62 \mathrm{~cm}$ ) and were asymptomatic at the time of testing. The characteristics of the patients at the time of the pulmonary function test and results of the test are shown in Table 2.

Pulmonary function tests showed forced vital capacity in the normal range and reduced expiratory flows (below 2 Z-scores) in most patients (Figure 1).

\section{Multivariable analysis}

Multiple linear regression was used to analyze the relationship between maximal expiratory flows, inflammatory response and perinatal events. After adjusting for differences in lung volume there was a significant negative correlation between TNF- $\alpha$ levels in airway secretions and maximal expiratory flows. $\mathrm{FEF}_{50}, \mathrm{FEF}_{75}, \mathrm{FEF}_{85}, \mathrm{FEF}_{25-75}$, and $\mathrm{FEV}_{0.5}$ were all significantly associated with TNF- $\alpha$ concentration with a correlation coefficient of $-0.60(\mathrm{P}=0.04),-0.76(\mathrm{P}=0.02)$, $-0.75(\mathrm{P}=0.03),-0.71(\mathrm{P}=0.02)$, and -0.39 $(\mathrm{P}=0.03)$, respectively. We did not detect an association between lung function variables and birth weight, sex, maternal infection, mechanical ventilation, or supplementary oxygen. IL-10 was not associated with any of the above variables.

\section{Discussion}

The present study shows that TNF- $\alpha$ and IL-10 are detectable in the TBL of preterm infants between 24 and 32 weeks of gestational age. There was a significant associa- tion between TNF- $\alpha$ and IL-10 concentrations and the length of time between rupture of the amniotic membrane and delivery. Since a significant portion of our population died due to sepsis we were unable to follow a large group of infants with the lung function tests. Nevertheless, we were still able to detect a significant negative association between the intensity of the inflammatory response, expressed by TNF- $\alpha$ levels in airway secretions, and maximal expiratory flows.

We did not detect a specific pattern of TNF- $\alpha$ or IL-10 production during the mechanical ventilation period, as has also shown in previous studies $(4,9,22,28-30)$.

Inflammatory cells and cytokines have been described in the airways of premature infants. This inflammatory response can be triggered by many factors, including mechanical ventilation, oxygen free radicals, increase of pulmonary flow due to the patent ductus arteriosus, and pulmonary and systemic infection acquired before or after birth (13). There are convincing data showing that inflammation contributes to pulmonary damage in preterm infants (22).

Many investigators believe that TNF- $\alpha$

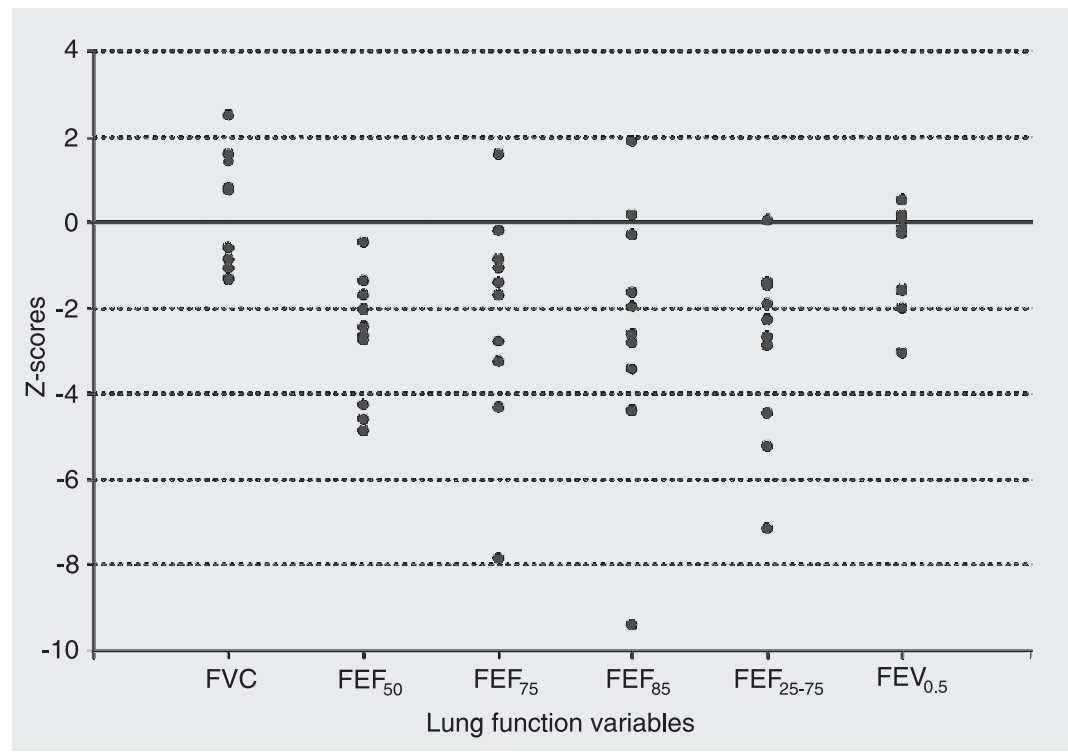

Figure 1. Lung function variables reported as Z-scores from the subjects studied. FVC = forced vital capacity. FEF = forced expiratory flow rate; FEV = forced expiratory volume. 
and IL-10 do play an important role in the airway inflammatory response of ventilated premature newborns $(9,10,22,29,31-33)$. In the present study, TNF- $\alpha$ and IL-10 were detected in significant levels in 67 and 26\% of the samples collected, respectively. The absence of a "control" group does not allow us to conclude whether these frequencies or concentrations were significantly increased or decreased compared to normal children or even to non-ventilated premature babies. We did not find any relationship between TNF$\alpha$ or IL-10 concentrations and gestational age, duration of mechanical ventilation and the time of oxygen therapy. However, we did detect a significant association between time of rupture of membranes and the increase of the inflammatory process in the airways of preterm infants. These findings may suggest that pulmonary inflammation could be present even before birth through intrauterine exposure to inflammatory cytokines released due to maternal perinatal infections or prolonged rupture of membranes $(3,34)$.

We also detected a significant negative association between TNF- $\alpha$ concentrations on the second day after intubation and all expiratory flows measured in the first months of life. To our knowledge, no previous study investigated the association between the inflammatory response and lung function in infants. This observation offers additional evidence that the damage induced by inflammation can be subtle and clinically undetectable but still significant, with CLD occurring in one extreme of the spectrum. In our sample, for example, the patient with lowest Z-scores for expiratory flows was not diagnosed as having CLD.

The obstructive airway pattern that develops after the sequence of infection, inflammatory response, prematurity, and mechanical ventilation is complex (35). Additionally, interaction between these components may increase the loss of lung function. Van Marter et al. (36) observed that prolonged mechanical ventilation and postnatal infection interact with antenatal infection, increasing the risk of CLD. Probably due to the small sample size, our data did not show a significant correlation between gestational age, birth weight, mechanical ventilation, or oxygen therapy and reduction of expiratory flows. We were also unable to detect an association between IL-10 concentrations (or the IL-10:TNF- $\alpha$ ratio) and expiratory flows.

In the present study, TBL was used as the method of analysis of the pulmonary inflammatory response in preterm infants. There is no standard method for this purpose, such as bronchoalveolar lavage through flexible bronchoscopy in infants and older children, due to the technical limitations of endotracheal tube size in preterm infants. However, many studies have found suitable methods for intubated infants by using non-bronchoscopic bronchoalveolar lavage techniques $(4,9,10,22,28-30,33,37)$. The use of markers for the dilution factor (such as IgA, urea or albumin), did not prove to be a reliable method $(9,38)$. Thus, since an appropriate denominator of reference for correcting the diluting effects of the lavage has not been universally accepted, calculating the cytokine concentrations using the volume of TBL return $(\mathrm{pg} / \mathrm{mL})$ has been the method of choice in studies for the analysis of solutes in bronchoalveolar lavages $(9,22,29)$. The non-selective TBL method was used in the present study because it is part of the technique of routine endotracheal tube aspiration and the method of choice of many previous studies $(4,9,10,22,28-30,33)$.

In conclusion, we were able to show that the intensity of the airway inflammatory response during the first days of life was associated with subsequent lung function abnormalities measured later. This observation also suggests that lung inflammation may have an important effect on lung development at least during the first months of life even in asymptomatic prematurely born infants. 
Further investigations are required to determine the role of other pro- or antiinflammatory cytokines in the development of CLD. The development of therapeutic and preventive alternatives to reduce the morbidity and lung function abnormalities that persist during the first months of life in this group of patients should generate a great impact in terms of a better prognosis of respiratory disease for these children.

\section{Acknowledgments}

The authors wish to thank the nurses and medical staff of the Neonatal Intensive Care Unit of Hospital São Lucas, Porto Alegre, RS, Brazil, and especially Dr. Renato Fiori, head of the Unit, for his invaluable cooperation with this research.

\section{References}

1. De Dooy JJ, Mahieu LM, Van Bever HP. The role of inflammation in the development of chronic lung disease in neonates. Eur $J$ Pediatr 2001; 160: 457-463.

2. Welty SE. Is oxidant stress in the causal pathway to bronchopulmonary dysplasia? NeoReviews 2000; 1: 6-10.

3. Lyon A. Chronic lung disease of prematurity. The role of intra-uterine infection. Eur J Pediatr 2000; 159: 798-802.

4. McColm JR, Stenson BJ, Biermasz N, Mclntosh N. Measurement of interleukin 10 in bronchoalveolar lavage from preterm ventilated infants. Arch Dis Child Fetal Neonatal Ed 2000; 82: F156-F159.

5. Stark AR. High-frequency oscillatory ventilation to prevent bronchopulmonary dysplasia - are we there yet? N Engl J Med 2002; 347: 682-684.

6. Yoon BH, Romero R, Kim KS, Park JS, Ki SH, Kim BI, et al. A systemic fetal inflammatory response and the development of bronchopulmonary dysplasia. Am J Obstet Gynecol 1999; 181: 773-779.

7. Fitzgerald DA, Mesiano G, Brosseau L, Davis GM. Pulmonary outcome in extremely low birth weight infants. Pediatrics 2000; 105: 1209-1215.

8. Jobe AH, Bancalari E. Bronchopulmonary dysplasia. Am J Respir Crit Care Med 2001; 163: 1723-1729.

9. Jonsson B, Li YH, Noack G, Brauner A, Tullus K. Downregulatory cytokines in tracheobronchial aspirate fluid from infants with chronic lung disease of prematurity. Acta Paediatr 2000; 89: 1375-1380.

10. Jonsson B, Tullus K, Brauner A, Lu Y, Noack G. Early increase of TNF alpha and IL-6 in tracheobronchial aspirate fluid indicator of subsequent chronic lung disease in preterm infants. Arch Dis Child Fetal Neonatal Ed 1997; 77: F198-F201.

11. Northway WH Jr. Bronchopulmonary dysplasia: twenty-five years later. Pediatrics 1992; 89: 969-973.

12. Northway WH Jr. An introduction to bronchopulmonary dysplasia. Clin Perinatol 1992; 19: 489-495.

13. Bancalari $E$. Changes in the pathogenesis and prevention of chronic lung disease of prematurity. Am J Perinatol 2001; 18: 1-9.

14. An $\mathrm{H}$, Nishimaki $\mathrm{S}$, Ohyama M, Haruki $A$, Naruto $T$, Kobayashi $N$, et al. Interleukin-6, interleukin-8, and soluble tumor necrosis factor receptor-I in the cord blood as predictors of chronic lung disease in premature infants. Am J Obstet Gynecol 2004; 191: 1649-1654.

15. Bancalari E. Epidemiology and risk factors for the "new" bronchopulmonary dysplasia. NeoReviews 2000; 1: 2-5.

16. Groneck P, Speer CP. Inflammatory mediators and bronchopulmonary dysplasia. Arch Dis Child Fetal Neonatal Ed 1995; 73: F1-F3.

17. McColm JR, McIntosh N. Interleukin-8 in bronchoalveolar lavage samples as predictor of chronic lung disease in premature infants. Lancet 1994; 343: 729.

18. Schultz C, Tautz J, Reiss I, Moller JC. Prolonged mechanical ventilation induces pulmonary inflammation in preterm infants. Biol Neonate 2003; 84: 64-66.

19. Deng $H$, Mason SN, Auten RL Jr. Lung inflammation in hyperoxia can be prevented by antichemokine treatment in newborn rats. Am J Respir Crit Care Med 2000; 162: 2316-2323.

20. Kotecha S. Cytokines in chronic lung disease of prematurity. Eur $J$ Pediatr 1996; 155 (Suppl 2): S14-S17.

21. Kotecha S, Chan B, Azam N, Silverman M, Shaw RJ. Increase in interleukin-8 and soluble intercellular adhesion molecule-1 in bronchoalveolar lavage fluid from premature infants who develop chronic lung disease. Arch Dis Child Fetal Neonatal Ed 1995; 72: F90-F96.

22. Jones CA, Cayabyab RG, Kwong KY, Stotts C, Wong B, Hamdan H, et al. Undetectable interleukin (IL)-10 and persistent IL-8 expression early in hyaline membrane disease: a possible developmental basis for the predisposition to chronic lung inflammation in preterm newborns. Pediatr Res 1996; 39: 966-975.

23. Dudley DJ, Hunter C, Mitchell MD, Varner MW. Amniotic fluid interleukin-10 (IL-10) concentrations during pregnancy and with labor. $J$ Reprod Immunol 1997; 33: 147-156.

24. Ozdemir A, Brown MA, Morgan WJ. Markers and mediators of inflammation in neonatal lung disease. Pediatr Pulmonol 1997; 23: 292-306.

25. de Blic J, Midulla F, Barbato A, Clement A, Dab I, Eber E, et al. Bronchoalveolar lavage in children. ERS Task Force on bronchoalveolar lavage in children. European Respiratory Society. Eur Respir J 2000; 15: 217-231.

26. Feher A, Castile R, Kisling J, Angelicchio C, Filbrun D, Flucke R, et al. Flow limitation in normal infants: a new method for forced expiratory maneuvers from raised lung volumes. J Appl Physiol 1996; 80: 2019-2025.

27. Jones M, Castile R, Davis S, Kisling J, Filbrun D, Flucke R, et al. Forced expiratory flows and volumes in infants. Normative data and lung growth. Am J Respir Crit Care Med 2000; 161: 353-359.

28. Huang HC, Yang MY, Huang CB, Yang KD. Profiles of inflammatory cytokines in bronchoalveolar lavage fluid from premature infants with respiratory distress disease. J Microbiol Immunol Infect 2000; 33: $19-24$

29. Oei J, Lui K, Wang H, Henry R. Decreased interleukin-10 in tracheal aspirates from preterm infants developing chronic lung disease. Acta Paediatr 2002; 91: 1194-1199. 
30. Beresford MW, Shaw NJ. Detectable IL-8 and IL-10 in bronchoalveolar lavage fluid from preterm infants ventilated for respiratory distress syndrome. Pediatr Res 2002; 52: 973-978.

31. Coalson JJ, Winter VT, Siler-Khodr T, Yoder BA. Neonatal chronic lung disease in extremely immature baboons. Am J Respir Crit Care Med 1999; 160: 1333-1346.

32. Naik AS, Kallapur SG, Bachurski CJ, Jobe AH, Michna J, Kramer $\mathrm{BW}$, et al. Effects of ventilation with different positive end-expiratory pressures on cytokine expression in the preterm lamb lung. Am J Respir Crit Care Med 2001; 164: 494-498.

33. Tullus K, Noack GW, Burman LG, Nilsson R, Wretlind B, Brauner A. Elevated cytokine levels in tracheobronchial aspirate fluids from ventilator treated neonates with bronchopulmonary dysplasia. Eur $J$ Pediatr 1996; 155: 112-116.

34. Yoon BH, Romero R, Jun JK, Park KH, Park JD, Ghezzi F, et al. Amniotic fluid cytokines (interleukin-6, tumor necrosis factor-alpha, interleukin-1 beta, and interleukin-8) and the risk for the develop- ment of bronchopulmonary dysplasia. Am J Obstet Gynecol 1997; 177: 825-830.

35. Jobe $\mathrm{AH}$. Antenatal factors and the development of bronchopulmonary dysplasia. Semin Neonatol 2003; 8: 9-17.

36. Van Marter LJ, Dammann O, Allred EN, Leviton A, Pagano M, Moore $\mathrm{M}$, et al. Chorioamnionitis, mechanical ventilation, and postnatal sepsis as modulators of chronic lung disease in preterm infants. J Pediatr 2002; 140: 171-176.

37. Murch SH, MacDonald TT, Wood CB, Costeloe KL. Tumour necrosis factor in the bronchoalveolar secretions of infants with the respiratory distress syndrome and the effect of dexamethasone treatment. Thorax 1992; 47: 44-47.

38. Bagchi A, Viscardi RM, Taciak V, Ensor JE, McCrea KA, Hasday JD. Increased activity of interleukin- 6 but not tumor necrosis factoralpha in lung lavage of premature infants is associated with the development of bronchopulmonary dysplasia. Pediatr Res 1994; 36: 244-252. 